\title{
TEORIA EWOLUCJI KULTUROWEJ I SPOŁECZNEJ WALTERA GARRISONA RUNCIMANA
}

\section{EWOLUCJONIZM A SOCJOLOGIA}

Prezentowana w niniejszym artykule koncepcja stanowi jeden $\mathrm{z}$ najnowszych rozdziałów w burzliwej historii relacji między darwinizmem a socjologią. Historię tę warto na wstępie w dużym skrócie przypomnieć. Pierwsze obiecujące zastosowania teorii doboru naturalnego do materii społecznej przeprowadzone przez Herberta Spencera (do relacji między społeczeństwami) i Émila Durkheima (do relacji wewnątrzspołecznych) zostały wkrótce przez ich epigonów zastosowane do celów ideologiczno-politycznych. Występując pod szyldem „darwinizmu społecznego", na długie dziesięciolecia skompromitowały sam pomysł. Choć w dwudziestym wieku wielu uczonych próbowało ożywić ewolucjonistyczny paradygmat w naukach społecznych (Talcott Parsons, Robert Bellah i Gerhard Lenski w socjologii, Leslie White, Julian Steward, Marshall Sahlins - antropologii, Gordon V. Childe - archeologii), to najczęściej ich punktem wyjścia były teorie Edwarda B. Tylora i Lewisa Morgana. Podkreślić jednak należy, że zarówno podejście Tylora, jak i Morgana reprezentuje zupełnie inne niż w darwinizmie rozumienie terminu ewolucja, bliższe zreszta sensowi etymologicznemu, który oznacza „,rozwijanie” (np. zwoju pergaminu). Modelem tych teorii jest więc raczej rozwój ontogenetyczny, najczęściej opisywany poprzez określone stadia, uzewnętrzniające właściwości obecne w zalążkach już w fazie genezy. Poszukiwanie sekwencji stadiów (mniej lub bardziej uniwersalnej) skłania badaczy rozumiejących ewolucję w ten sposób do przedkładania metody porównawczej nad studia przypadków i nacisku na metodę genetyczną. Takie rozumienie ewolucji określić też można jako transformistyczne w przeciwieństwie do selekcyjnego, właściwego darwinizmowi, a które sprowadza się zasadniczo do dwóch etapów: wytwarzania dziedzicznej różnorodności oraz selekcji wśród wariantów. Teoria Darwina stanowi więc typowy przykład teorii wariacyjnych, w których zmiana ewolucyjna wynika z różnic między składowymi danej populacji ${ }^{1}$. Neoewolucjonizm dwudziestowieczny, nawet jeśli czerpał również z koncepcji Spencera czy Durkheima, to właściwie wyłącznie z transformacyjnych wątków ich teorii.

Próby bezpośredniego zastosowania darwinizmu do kultury i społeczeństwa podejmowane były natomiast ze strony nauk biologicznych. Można mówić

1 J. Fracchia, R. C. Lewontin, Does Culture Evolve?, „History and Theory” 38, 1999, nr 4, s. 61. 
o trzech takich nurtach charakteryzujących się odmienną relacją między teoria biologiczna a rzeczywistością społeczną ${ }^{2}$ :

1. Socjobiologia - w rozumieniu Edwarda O. Wilsona - usiłowała znaleźć biologiczne podstawy społecznych zachowań ludzi, pewne uniwersalne, wynikające z ludzkiej natury ograniczenia czy tendencje. Pod wpływem krytyki, z jaką się spotkała $^{3}$, zrodziła się psychologia ewolucyjna, która obecnie wchodzi w bliskie i płodne związki z naukami kognitywnymi. Rezultaty tego nurtu na gruncie socjologii implementuje Stephen K. Sanderson, jednakże - jak przyznaje podejście to sprawdza się najlepiej $\mathrm{w}$ zagadnieniach związanych $\mathrm{z}$ szeroko rozumianą płciowością (płeć, rodzaj, pokrewieństwo, rodzina itp.).

2. Drugi nurt przyznaje kulturze pełną niezależność, jednak bada ją gównie z perspektywy jej biologicznego znaczenia dla przeżycia i reprodukcji ludzkich populacji. Najciekawsze przykłady tego ujęcia można znaleźć wśród prac reprezentujących tak zwaną teorię podwójnego dziedziczenia (dual inheritance theory), stosująca metody genetyki populacyjnej do modelowania wzajemnego wpływu kultury i genów.

3. Trzeci nurt odrzuca biologiczne kryteria oceny kultury i bada ja jako zjawisko podlegające mechanizmom darwinowskim. Najbardziej znanym przykładem tego „darwinizmu bez biologii” jest niewatpliwie memetyka, dyscyplina zapoczątkowana przez Richarda Dawkinsa, autora pojęcia dziedziczonej społecznie jednostki informacji kulturowej, czyli memu.

Ostatnie z ujęć, a zwłaszcza jego memetyczna realizacja, choć wydaje się mi najciekawsze $\mathrm{z}$ punktu widzenia socjologii, nie spotkało się (podobnie zreszta jak poprzednie) z przychylną odpowiedzia ze strony nauk społecznych. Postrzegane były jako przejaw połączenia arogancji właściwej reprezentantom „,twardej” (czyli ,jedynej prawdziwej”) nauki z - faktyczna - ignorancja w dziedzinie antropologii kulturowej, historii, a szczególnie socjologii ${ }^{4}$.

Nastawienie do darwinizmu i biologii wydaje się w naukach społecznych zmieniać, zwłaszcza w archeologii i ekonomii badacze stosujący darwinowskie podejście nie należą już do rzadkości. Ostatecznie zmianę da się zauważyć również w socjologii, wraz z tym, co ośmieliłbym się (nieco uprzedzająco) nazwać „trzecia falą ewolucjonizmu” w tej dyscyplinie. Wiążę ją z wydaniem takich prac, jak: Human Institutions. A Theory of Societal Evolution ${ }^{5}$ oraz pierwszego tomu Theoretical Principles of Sociology ${ }^{6}$ Jonathana Turnera; Ecological-Evolutionary Theory. Principles and Applications ${ }^{7}$, w której Gerhard Lenski

\footnotetext{
${ }^{2}$ E. Sober, Philosophy of Biology, Westview Press, Boulder, 2000, s. 213-214.

${ }^{3}$ Por. B. Szacka, Wstęp, w: eadem (red.), Cztowiek, zwierze spoteczne, Czytelnik, Warszawa, 1991.

${ }^{4}$ Por. D. Sperber, An Objection to the Memetic Approach to Culture, w: R. Aunger (red.), Darwinizing Culture: The Status of Memetics as a Science, Oxford University Press, Oxford 2000, s. 163-173; A. Kuper, If Memes Are the Answer, What Is the Question?, w: R. Aunger (red.), op. cit., s. 175-188; M. Golka, Pamięć spoteczna $i$ jej implanty, Scholar, Warszawa, 2009.

${ }^{5}$ J. H. Turner, Human Institutions. A Theory of Societal Evolution, Rowman \& Littlefield Publishers, Inc., Lanham 2003.

${ }^{6}$ J. H. Turner, Theoretical Principles of Sociology, t. 1: Macrodynamics, Springer, New York-London-Heidelberg 2010.

${ }^{7}$ G. Lenski, Ecological-Evolutionary Theory. Principles and Applications, Paradigm Publishers, Boulder, London 2005. Por. też P. Nolan, G. Lenski, Human Societies. An Introduction to Macrosociology, McGraw-Hill Book Company, New York 1995.
} 
zebrał teoretyczne założenia swojego ewolucjonistycznego podejścia; pracami o makroewolucji społecznej Stephena K. Sandersona ${ }^{8}$; a także A Treatise on Social Theory ${ }^{9}$ oraz The Theory of Cultural and Social Selection ${ }^{10}$ Waltera G. Runcimana. Wszyscy wymienieni autorzy podpisuja się dziś pod tezą czołowego reprezentanta „,drugiej fali” Talcotta Parsonsa, że brak ciągłości, jaka nauki społeczne zakładały między ewolucją organiczną a kulturową, nie jest już dłużej usprawiedliwiony w kontekście współczesnej biologii ${ }^{11}$. Choć nawiązuja do darwinizmu w bardzo różnym, a często dość ograniczonym zakresie, to same te nawiązania świadczą, że kurz po dyskusjach wokół socjobiologii, jak się wydaje, już opadł i nazwisko autora $O$ powstawaniu gatunków przestaje wśród socjologów budzić kontrowersje.

\section{NEODARWINIZM JAKO SOCJOLOGIA}

Najdalej posuniętą próbą wprowadzenia darwinizmu do socjologii są prace profesora socjologii Trinity College (Uniwersytetu w Cambridge) i Akademii Brytyjskiej - Waltera Garrisona Runcimana. Próba ta jest również najodważniejszym zerwaniem z tradycją ewolucjonizmu klasycznego. O ile większość reprezentantów ,trzeciej fali” stara się twórczo rozwijać myśli Comte’a, Spencera, Marksa i Durkheima, o tyle Runcinam zdecydowanie odrzuca ich dorobek, zarzucając im podejście teleologiczne i nieprzystawalność do reprezentowanego przez siebie paradygmatu neodarwinowskiego ${ }^{12}$. Podejście to $\mathrm{w}$ biologii wyznaczaja takie nazwiska, jak Ronald A. Fisher, John Maynard Smith, George C. Williams, William D. Hamilton czy ich popularyzator - Richard Dawkins. Ewolucję ujmuje się w nim jako proces „dziedzicznej różnorodności i konkurencyjnej selekcji informacji, która oddziałuje na zachowania w fenotypie". Takie przedefiniowanie - z procesu, któremu podlegają osobniki (u Darwina), na proces, któremu podlega informacja (u selekcjonistów), umożliwia - zdaniem Runcimana - zastosowanie darwinizmu do kultury i społeczeństwa, jako systemów, gdzie również zachodzi transmisja informacji z pokolenia na pokolenie, której towarzyszą modyfikacje. Innymi słowy, w takim ujęciu darwinizm przestaje być już „,ylko metafora”, ale zostaje uogólniony do postaci, która znajduje zastosowanie wszędzie, gdzie zachodzi proces dziedziczonej różnorodności informacji połączony z jej selekcją. Runciman podkreśla:

\footnotetext{
8 S. K. Sanderson, Macrosociology. An Introduction to Human Societies, HarperCollins, New York 1995; idem, Social Transformations: A General Theory of Historical Development, Rowman \& Littlefield Publishers, Inc., Lanham 1999.

${ }^{9}$ W. G. Runciman, A Treatise on Social Theory, t. 2: Substantive Social Theory, Cambridge University Press, Cambridge 1989.

${ }^{10}$ W. G. Runciman, The Theory of Cultural and Social Selection, Cambridge University Press, Cambridge 2009.

11 T. Parsons, Societies. Evolutionary and Comparative Perspectives, Prentice-Hall, Inc., Englewood Cliffs, New Jersey, 1966, s. 109.

${ }^{12}$ W. G. Runciman, Forgetting the Founders, „Sociological Review” 56, 2008, nr 3, s. 358-369; M. Ossewaarde, Forgetting the Founders? - Reply to Runciman, ,Sociological Review” 57, 2009, nr 2, s. 353-356; W. G. Runciman, Rejoinder to „Forgetting the founders?”, „Sociological Review” 57, 2009, nr 2, s. 357-359.
} 
„,informacja nie jest metafora, jest rzeczywistością. Nie ma innej rzeczy, która by zastępowała"13. Zauważmy jednak, że teza ta wcale nie jest tak oczywista, jeśli się przyjrzeć dyskusji toczącej się głównie na łamach „Philosophy of Science" po artykule Johna Maynarda Smitha. Zdaniem przynajmniej niektórych z dyskutantów informacja jest metaforą w samej biologii, stanowi nieuprawniony antropomorfizm. Nawet jeśli zgodzimy się, że - przynajmniej w pewnym sensie - w obu przypadkach ewolucji (biologicznej i kulturowej) mamy do czynienia $\mathrm{z}$ dziedziczeniem informacji, to bez uwzględnienia kontekstu, w jakim ta informacja w obu wypadkach występuje, pojawić się moga uproszczenia o bardzo negatywnych konsekwencjach dla teorii.

Poza zrębem teorii neodarwinowskiej Runciman przejmuje jeszcze z biologii ewolucjonistycznej zasadnicze nastawienie badawcze, które streszcza się w pytaniu, będącym metodologiczną dyrektywą: „co właściwie się tutaj dzieje?" ${ }^{14}$. W socjologii oznacza to rezygnację z prób konstruowania wszechogarniających schematów ewolucji ludzkości, które miałyby wszystko wyjaśnić, ale skupienie się na dostarczeniu narzędzi, za pomocą których badacz mógłby rzucić nowe światło na konkretne zjawiska. Wyjaśnienie tego rodzaju przybiera więc często formy pewnej historycznej narracji, budowania scenariusza najbardziej prawdopodobnego przebiegu wypadków. Jest to podejście, które spotkać się może ze strony socjologów z zarzutem, że to tylko interpretacja ex post facto ${ }^{15}$. Jak na to zwraca uwagę Ernst Mayr (współtwórca nowoczesnej syntetycznej teorii ewolucji), krytycyzm taki wiąże się z filozofią nauki oparta na fizyce, jako nauce wzorcowej, nieznajdująca zastosowania $\mathrm{w}$ biologii ewolucjonistycznej. Co więcej, jak sugeruje ten autor, podejście historyczne może się okazać jedynym właściwym w wyjaśnianiu zjawisk wyjątkowych, niepowtarzalnych ${ }^{16}$. Sądzę, że Runciman wskazał tu właściwą drogę do przezwyciężenia bodaj czy nie największej słabości dotychczasowych prób socjologicznego ewolucjonizmu, jaka jest ich schematyzm i przywiązanie do perspektywy makrosocjologicznej. Darwinizm tymczasem nie jest teoria jedynie ,,wielkiego drzewa życia”, ale zdolny jest rzucić nowe światło na niemal każdy, najdrobniejszy szczegół świata ożywionego. Zdanie Theodosiusa Dobzhanskyego, że nic w biologii nie ma sensu, dopóki nie zostanie oświetlone w perspektywie teorii ewolucji, można więc rozumieć bardzo szeroko: opozycją dla „,nic” nie jest tu „,całość”, ale „,wszystko”. Źródłem wspomnianego schematyzmu dawnych i wielu współczesnych teorii ewolucji jest, w moim przekonaniu, brak precyzji w ujmowaniu przedmiotu ewolucji. Teorie te maja opisywać ewolucje „ludzkości”, „,społeczeństwa”, „kultury” czy poszczególnych instytucji (np. religii) pojętych abstrakcyjnie. Kontrastuje to zasadniczo z podejściem Darwina, który szukał mechanizmów powstania gatunków (czyli konkretnych bytów biologicznych), teorii tłumaczących konkretne adaptacje, nie zaś „życia w ogóle”.

${ }^{13}$ W. G. Runciman, The Theory..., s. 7.

14 Ibidem, s. 6.

${ }^{15}$ Por. R. K. Merton, Teoria socjologiczna i struktura społeczna, tłum. E. Morawska, J. Wertenstein-Żuławski, PWN, Warszawa 1982, s. 160-162.

${ }^{16}$ E. Mayr, What Evolution Is, Phoenix, London 2002, s. 61. 
Dlatego słusznie, moim zdaniem, Runciman dowartościowuje na gruncie ewolucjonizmu badania idiograficzne. Szczegółowa analiza idiograficzna jest niezbędna, gdyż podobieństwa obserwowane na poziomie społeczeństwa czy kultury mogą mieć różne wyjaśnienie:

- ich wspólna forma może wynikać z tego, że jako adaptacje pełnią tę samą funkcję. Jest to rozumowanie w kategoriach ewolucji konwergentnej, zakładającej, że podobne środowisko spotyka się z podobną odpowiedzią;

- podobieństwa moga wynikać ze wspólnego pochodzenia, zakłada się wówczas, że wpływ środowiska jest mniej istotny niż kulturowe czy społeczne dziedziczenie ${ }^{17}$

- mogą być też rezultatem dyfuzji, czyli transmisji bocznej danej idei ${ }^{18}$.

Runciman odrzuca jednak również analizę jednostkowych przypadków w oderwaniu od komparatystyki. Tak jak współwystępowanie w czasie nie dowodzi istnienia przyczynowości, tak też następstwo w czasie nie dowodzi istnienia procesu leżącego u jego podstaw ${ }^{19}$.

Choć Runciman daleki jest od redukowania zjawisk społecznych do biologicznych, to jego zakorzenienie teoretyczne we wspomnianym ultraselekcjonistycznym nurcie neodarwinizmu owocuje innego rodzaju redukcjonizmami.

\section{REDUKCJA MECHANIZMÓW DO DOBORU}

Pierwszą redukcję ilustruje następujące zdanie: „Krótka odpowiedź neodarwinowskiego socjologa na pytanie, »co tu się dzieje«, jest następująca: »to przejawiające się $\mathrm{w}$ fenotypowych zachowaniach wyniki transferu informacji na poziomie populacyjnym «" ${ }^{20}$. Runciman, wzorem ultraselekcjonistów w biologii, redukuje wszystkie procesy mogące mieć wpływ na wynik wyłącznie do przepływu najmniejszej jednostki informacji (memu). Tymczasem we współczesnej biologii coraz mniej jest badaczy, którzy sprowadzają wszystkie mechanizmy do doboru naturalnego, a genowy poziom tego doboru uważany jest tylko za jeden $\mathrm{z}$ wielu, i to raczej mniej istotny ${ }^{21}$. Tym bardziej ryzykowna wydaje mi się próba redukcji wszystkich wyjaśnień społecznych do jednego mechanizmu.

Jak trafnie zauważają krytycy Runcimana, w jego podejściu nie ma miejsca na przykład na zdarzenia losowe bądź wpływ wysoko postawionych albo charyzmatycznych jednostek na przebieg wydarzeń ${ }^{22}$. Pominięcie roli jednostkowych przywódców Runciman uzasadnia w ten sposób, że niezależnie od tego, co takie postacie same myślą o swej historycznej roli, to sa jedynie „,inicjatorami” pewnych zmian, „których poszerzonego efektu fenotypowego i długoterminowego reprodukcyjnego przystosowania nie mogli ani przewidzieć,

${ }^{17}$ W. G. Runciman, The Theory..., s. 195.

${ }^{18}$ Ibidem, s. 33.

${ }^{19}$ Ibidem, s. 197.

${ }^{20}$ Ibidem, s. 29.

${ }^{21}$ Por. E. Mayr, The Objects of Selection, „Proceedings of the National Academy of Sciences of the USA" 94, 1997, s. 2091-2094; D. J. Futuyma, Ewolucja, tłum. J. Radwan, Uniwersytet Warszawski, Warszawa 2008, s. 259-262.

${ }^{22}$ J. Fracchia, R. C. Lewontin, The Price of Metaphor, ,History and Theory” 44, 2005, nr 1, s. 25 i 27. 
ani też kontrolować" ${ }^{23}$. Innymi słowy, na etapie doboru charyzmatyczny przywódca czy wynalazca musi być widziany tak samo, jak przypadkowe czynniki zmian. Siły będące przyczyną pojawienia się nowej idei lub decyzji politycznej nie są tymi samymi, które działają na etapie selekcji, czyli tymi, które przesądzą o sukcesie bądź porażce ${ }^{24}$. Moim zdaniem, Runciman ma tu rację tylko formalnie: przywódca sytuuje się w tym samym miejscu modelu darwinowskiego (jako źródło zmienności cech) co czynniki losowe, można by przedstawić też szereg spektakularnych przykładów, gdy społeczne lub polityczne dzieło wymknęło się z rąk swego twórcy. Jednakże przywódca obdarzony wyobraźnią i wiedzą dokonuje realnie innych zmian niż przywódca wyobraźni pozbawiony czy też czysty przypadek. Dzięki wiedzy o faktycznie działających w społeczeństwie siłach selekcyjnych może ,,przeskoczyć” w wyobraźni jeden lub kilka etapów działania doboru społecznego. Dokonuje on porównania możliwych rozwiązań danego problemu albo choćby konsekwencji podjęcia i niepodjęcia decyzji, konfrontując je ze znanymi sobie okolicznościami. Całość odbywa się w formie symulacji, eksperymentu myślowego, a uwzględniane warunki będą zwykle mniej lub bardziej różnić się od warunków, w których konsekwencje wynalazku lub decyzji będą się uzewnętrzniać. Jednak zmienność w świecie społecznym i kulturowym nie jest chyba aż tak wielka, by wykluczyć hipotezę, że te nielosowo wprowadzone zmiany będą się w ostatecznym procesie ewolucyjnego doboru zachowywać inaczej niż czysto losowe.

Sądzę zatem, że socjologia ewolucjonistyczna winna zbudować kompletna teorię czynników zmienności społecznej i kulturowej. Taka teoria musi obejmować różne typy oddziaływań zarówno czysto losowych, jak i populacyjnych, ale także jednostkowych. Tymczasem, mimo werbalnych zaprzeczeń, selekcjonistyczny program Runcimana charakteryzuje się skrajnym indywidualizmem metodologicznym, i to - jak zobaczymy - zarówno na poziomie społeczeństwa, jak i kultury:

Populacje, jakie musi analizować socjologia porównawcza, jeśli ma zdać sprawę z różnic, które wyewoluowały między kulturami i społeczeństwami, są populacjami jednostek czy pakietów informacji (włączając instrukcje czy strategie, jeśli są w deontycznej czy logicznej formie), nie zaś populacjami jednostkowych umysłów czy diad osób zajmujących instytucjonalne role, które są tych informacji nosicielami ${ }^{25}$.

\section{REDUKCJA SPOŁECZEŃSTWA DO WEADZY}

Druga formę redukcjonizmu, jakim charakteryzuje się koncepcja Runcimana, ma swe źródło w postulacie zawartym w notatkach Friedricha Nietzschego: ,,zamiast socjologii potrzebujemy teorii struktur władzy”. Runciman wprost przyznaje, że jego socjologia jest próbą realizacji tego postulatu ${ }^{26}$.

${ }^{23}$ W. G. Runciman, The Theory..., s. 31.

${ }^{24}$ Ibidem, s. 31.

25 Ibidem, s. 29.

${ }^{26}$ Ibidem, s. 221; por. idem, Can There Be a Nietzschean Sociology?, „Archives Européennes de Sociologie" 41, 2000, s. 3-21. 
Opierając się na pojęciu władzy, Runciman buduje cały swój socjologiczny system, a rozumie przez nie ,zdolność osób do wpływania zarówno poprzez zachęty, jak i sankcje na to co myśla, czuja, mówią czy czynią inne osoby poddane tej zdolności, wynikająca $\mathrm{z}$ posiadania instytucjonalnych, a nie osobistych atrybutów" ${ }^{27}$. Te instytucjonalne atrybuty zawarte są w roli, jaką osoby odgrywaja, a role to ,,pozycje ucieleśniające konsekwentnie powtarzające się wzorce instytucjonalnych zachowań, uzasadniane/określane przez wzajemnie podzielane wierzenia i oczekiwania dotyczące zdolności osób je zajmujących wprost lub pośrednio do wpływania wzajemnie na swoje zachowania" ${ }^{28}$. Pojęcie instytucji ma u niego charakter abstrakcyjny. Nie stosuje go do funkcjonalnie wyodrębnionych całości w ramach społeczeństwa, jak gospodarka, państwo, Kościoły itp., a jedynie przeciwstawia temu, co nieinstytucjonalne. Instytucje definiuje bowiem jako ,zestawy wzajemnie powiązanych praktyk, których zasady - wyraźnie lub nie sformułowane i powszechnie uznawane - odnosza się do dających się określić grup lub osób bez względu na decyzje tych osób lub ich zgodę" ${ }^{29}$. Przy czym - jak zobaczymy - kluczowa jest tu niezależność od woli i zgody jednostek. Obejmujący instytucjonalne role nowicjusze musza przestrzegać instrukcji również niezależnie od tego, jakie kulturowo transmitowane wierzenia czy postawy z sobą przynoszą ${ }^{30}$. Role są w istocie elementarnym składnikiem społeczeństwa, które Runciman definiuje następująco:

\begin{abstract}
Społeczeństwa są zatem w pełni zdefiniowane przez wyszczególnienie wszystkich ról zajmowanych przez ich członków, lokalizację tych ról jako zdefiniowanych przez odniesienie do wymiarów przestrzeni społecznej, w ramach których alokowana jest władza, i interesów zdefiniowanych w terminach utrzymania i powiększania władzy przypisanej do ról w jednym lub więcej z trzech wymiarów ${ }^{31}$.
\end{abstract}

Wspomniane trzy wymiary odnoszą się do trzech rodzajów władzy: ekonomicznej, ideologicznej i przymusowej ${ }^{32}$. Wychodząc od Marksowskiego terminu ,,sposób produkcji”, tworzy analogiczne terminy w pozostałych wymiarach, stąd mówi o „sposobach perswazji” oraz „,sposobach przymusu” ${ }^{33}$. Rozróżnienie to opiera się na dostępie i kontroli do - odpowiednio - środków produkcji, środków perswazji i środków przymusu ${ }^{34}$ (w tym ostatnim rodzaju pobrzmiewa echo Weberowskich środków administrowania). Na podstawie analizy historyczno-porównawczej Runciman wyróżnia osiem głównych sposobów produkcji, osiem sposobów perswazji oraz siedem przymusu. Całość ma stanowić klasyfikację porównywalna z Linneuszowa ${ }^{35}$. Taksonomia ta daje w rezultacie 448 kombinacji. Wyliczenie poszczególnych sposobów produkcji,

\footnotetext{
${ }^{27}$ Idem, A Treatise..., s. 2.

28 Ibidem, s. 3.

29 Ibidem, s. 2.

${ }^{30}$ Idem, The Theory..., s. 37.

${ }^{31}$ Idem, A Treatise..., s. 3.

${ }^{32}$ Ibidem, s. 16.

${ }^{33}$ Ibidem, s. 17.

${ }^{34}$ Ibidem, s. 12.

35 Ibidem, s. 58-59.
} 
przymusu czy perswazji nie jest uszeregowaniem chronologicznym (niewolnictwo pojawia się $\mathrm{w}$ pierwszej z tych list na końcu). Zauważmy jednak, że klasyfikacja Linneusza była hierarchiczna, nie polegała na krzyżowaniu ze soba arbitralnie wybranych kryteriów.

Większej roli nie odgrywają w socjologii Runcimana takie definiowane przez niego pojęcia, jak korporacje (formalne kolektywy osób o podobnym interesie, w odróżnieniu od nieformalnych stowarzyszeń), podobnie jak systakty (systact). Neologizmem tym zastępuje on szereg takich tradycyjnych kategorii służących do opisu zróżnicowania społecznego, jak: klasy, warstwy, stany, rangi, kasty, grupy interesu itp. Systakty to grupy czy kategorie osób, które ze względu na odgrywane role społeczne znajdują się w podobnym położeniu i posiadają podobne interesy w jednym lub więcej z trzech wymiarów społecznej struktury ${ }^{36}$. Nie wiadomo, dlaczego jeden, wszechobejmujący termin miałby być użyteczniejszy niż wiele bardziej szczegółowych. Być może jest to próba realizacji postulatu Nietzschego, by wszystko sprowadzić do jakiejś formy władzy. Ta bowiem nie jest pierwszym skojarzeniem nasuwającym się w odniesieniu do słowa klasa czy stan, nie mówiąc o grupie interesu.

\section{REDUKCJA SPOŁECZEŃSTWA DO PRAKTYK}

Powyższe sprowadzenie społeczeństwa do władzy jest jednak niewystarczajace z punktu widzenia postulatu zastosowania paradygmatu neodarwinowskiego do socjologii. Selekcjonizm, z którego czerpie Runciman, operuje bowiem na pewnych podstawowych jednostkach przekazywanej informacji. Jeśli zatem autor chce zbudować selekcjonistyczną teorię ewolucji społecznejmusi znaleźć taką podstawową jednostkę: społeczny odpowiednik genu. Za jednostkę dziedziczenia społecznego Runciman uznaje ,praktykę”. Praktyki to „funkcjonalnie zdefiniowane jednostki wzajemnego oddziaływania”. Sa one uzasadniane przez wzajemnie rozpoznane intencje osób wyznaczonych do odgrywania określonych ról oraz ich przekonania o wynikającej $\mathrm{z}$ tych ról zdolności wpływania na zachowanie drugich ${ }^{37}$.

Znaczenie praktyk w ewolucji społecznej polega na zwiększaniu lub zmniejszaniu władzy. Skoro są one podstawowym składnikiem struktury społecznej$\mathrm{z}$ nich składają się role, a z ról instytucje - to też rezultat konkurencji między praktykami przekłada się na zmiany ról i instytucji. Praktyki wygrywaja w konkurencji lub zamieraja w zależności od tego, czy są w stanie zapewnić więcej korzyści w walce o władzę dla danej roli ${ }^{38}$.

Nosicielami informacji zawartych $\mathrm{w}$ praktykach sa $\mathrm{w}$ tym wypadku diady oddziałujących na siebie ról instytucjonalnych ${ }^{39}$. Osoby je zajmujace muszą rozumieć ich znaczenie i akceptować zachęty i sankcje, które ręczą, że będą się

${ }^{36}$ Ibidem, s. 20.

${ }^{37}$ Ibidem, s. 41.

${ }^{38}$ Por. A. Carling, The Darwinian Weberian: W. G. Runciman and the Microfoundations of Historical Materialism, „Historical Materialism” 12, 2004, nr 1, s. 75.

${ }^{39}$ W. G. Runciman, The Theory..., s. 3. 
w stosunku do siebie odpowiednio zachowywać. Takimi diadami są dla niego na przykład ksiądz i parafianin, generał i żołnierze, ziemianin i dzierżawca. Nie wystarczy im jednak wiedzieć, co mają robić. By być tym, kim są, muszą także zaakceptować to, że są tym za sprawa praktyk, które wykonują. Są one wprawdzie renegocjowalne, ale nie podlegaja dowolnie ich woli. Podobnie kandydat na księdza nie tylko musi znać Biblię i sposób celebrowania mszy, ale musi zostać instytucjonalnie upoważniony i przypisany do parafii po zaakceptowaniu jego kwalifikacji ${ }^{40}$.

Praktyki nie sa zatem po prostu społecznymi działaniami, ale działaniami w kontekście instytucjonalnym, z władzą stojąca za odgrywanymi rolami, zachętami i sankcjami. Nasuwa się pytanie: co w takim razie z wszelkimi nieprzymuszonymi działaniami społecznymi, co ze spontanicznym oddaniem charyzmatycznemu przywódcy, z relacjami rodzinnymi, ze sferą regulowaną raczej przez obyczaje niż ściśle wyznaczone normy obramowane sankcjami? Wszystko to umieszcza Runciman w sferze kultury.

\section{REDUKCJA KULTURY DO MEMÓW}

Odpowiednikiem biologicznego genu i społecznej praktyki w sferze kultury jest dla Runcimana „mem”. Sam termin ukuty został przez Richarda Dawkinsa w książce Samolubny gen ${ }^{41}$. Sam Runciman dystansuje się od kontynuatorów Dawkinsa, określając Susan Blackmore i Kate Distin samozwańczymi memetykami ${ }^{42}$. W wypadku tej pierwszej jest to o tyle niesprawiedliwe, że sam Dawkins wielokrotnie wyrażał się o niej z aprobatą, podkreślając jej wielkie zasługi dla memetyki i pisząc wstęp do jej Maszyny memowej ${ }^{43}$. Wybór takiego czy innego słowa na określenie jednostki informacji kulturowej jest, zdaniem Runcimana, kwestią konwencji. Przejął on jednak nie tylko termin, ale też sporo $\mathrm{z}$ jego memetycznej treści. Jeśli za mem uznaje ,jednostkę czy pakiet informacji, z których składa się przekaz transmitowany z umysłu do umysłu przez naśladownictwo czy uczenie" ${ }^{44}$, to rozstrzyga już dwie rzeczy. Po pierwsze, że transmisja przebiega $\mathrm{z}$,umysłu do umysłu" ${ }^{45}$ - co jest socjologiczną fikcja, społeczeństwo nie składa się bowiem z „umysłów”, ale konkretnych, społecznie umiejscowionych jednostek, przy czym najistotniejsze informacje przekazywane są wielokanałowo (w procesie socjalizacji). Po drugie, przekaz ten odbywać się ma przez naśladownictwo i uczenie. Nie sa to bynajmniej kwestie oczywiste, jak pokazuje gorąca, i - jak się wydaje - niezakończona dyskusja na ten temat między memetykami. Dlatego za niewystarczające należy uznać zastrzeżenie Runcimana: „Pod warunkiem że

40 Ibidem, s. 59 .

${ }^{41}$ R. Dawkins, Samolubny gen, tłum. M. Skoneczny, Prószyński i S-ka, Warszawa 1996. Por. też idem, Fenotyp rozszerzony. Dalekosiężny gen, tłum. J. Gliwicz, Prószyński i S-ka, Warszawa 2003.

${ }^{42}$ W. G. Runciman, Forgetting the Founders, s. 362.

${ }^{43}$ R. Dawkins, Przedmowa, w: S. Blackmore, Maszyna memowa, tłum. N. Radomski, Rebis, Poznań 2002.

${ }^{44}$ W. G. Runciman, The Theory..., s. 3 i 53.

45 Ibidem, s. 56. 
termin ten nie zawiera żadnych wyprzedzających implikacji, co do tego, jak działa dobór kulturowy, i uwzględnia fakt, że memy są stale reinterpretowane i rekonstruowane w trakcie rozwoju ich nosicieli, socjologowie nie maja powodu odmawiać przyjęcia go do swego standardowego słownika" ${ }^{46}$. Jedyne wykroczenie Runcimana przeciw memetycznej ortodoksji polega na tym, że przyznaje on, iż memem może być nie tylko jednostka, ale też pakiet informacji (w tym drugim przypadku memetycy mówiliby o mempleksie $)^{47}$ oraz na mniejszym niż u memetyków nacisku na konieczność wierności kopiowania. Zdaje się jednak przyjmować tezę, iż mem jest replikatorem, czyli porcją informacji zdolną do samokopiowania ${ }^{48}$. Pojęcie replikatora odnosi też do jednostki dziedziczenia społecznego ${ }^{49}$, choć - jak zauważa Carling - bardzo trudno byłoby wykazać, że praktyki posiadaja właściwości samoreprodukowania się ${ }^{50}$. Warto zwrócić również uwagę, że właściwości takich nie posiadają również geny, prototypowe replikatory ${ }^{51}$.

Nie twierdzę, że dla słowa „mem” nie ma miejsca w socjologii, należałoby jednak mieć świadomość całego bagażu problemów, jaki ten termin ze sobą niesie, a bez rozwiązania których przynieść on może więcej szkody niż pożytku. Spójrzmy bowiem, jakie rozumienie kultury wyłania się, jeśli uznamy, że jej podstawowym składnikiem jest mem:

Dla celów socjologii porównawczej, pytaniem jest, dlaczego zwycięskie memy, które odróżniają jedna kulturę od innych, są zwycięzcami na poziomie populacji, czy ich reprodukcja i dyfuzja zachodzi poprzez instrukcje nauczycieli dla słuchaczy, przez naśladownictwo osób, które są modelami ról, ale nie są nawet świadome tego, że ktoś je naśladuje, przez kombinację obu, czy jeszcze coś pośredniego ${ }^{52}$.

Kultura, jako składająca się z rywalizujących memów, traci zatem - jak zauważyli Joseph Fracchia i Richard Lewontin ${ }^{53}$ - właściwości systemowe. Można się oczywiście spierać, czy kultura jest systemem (osobiście byłbym skłonny raczej bronić tezy, że składa się ze względnie niezależnych systemów kulturowych), z całą pewnością jednak odmawianie jej wszelkiej strukturyzacji, traktowanie jako zwykłej puli informacji czy też przestrzeni, w których informacje swobodnie przepływaja, jest zbyt daleko idącym uproszczeniem. Przede wszystkim dlatego, że sens każdego memu zależy, i w praktyce uczenia widać to bardzo wyraźnie, od innych memów. Sens terminu wyjaśnia się, odwołując do innych terminów. Istnieje jednak ważna różnica między memetyką a Runcimanem, na korzyść tego drugiego. Otóż wytłumaczenia losu danego memu szuka on nie w jego właściwościach, ale zapytuje, „,c było takiego

\footnotetext{
${ }^{46}$ Ibidem, s. 54.

47 Ibidem, s. 52.

48 Ibidem, s. 51.

49 Ibidem, s. 30.

${ }^{50}$ A. Carling, op. cit., s. 88.

${ }^{51}$ P. Godfrey-Smith, The Replicator in Retrospect, „Biology \& Philosophy” 15, 2000, s. 403-423.

${ }^{52}$ W. G. Runciman, The Theory..., s. 57.

53 J. Fracchia, R. C. Lewontin, Does Culture Evolve..., s. 71.
} 
$\mathrm{w}$ środowisku, co dało krytycznym mutacjom czy rekombinacjom informacji większe prawdopodobieństwo reprodukcji i dyfuzji niż ich rywalom" ${ }^{54}$.

Osobny problem wynika $\mathrm{z}$ faktu, że tak rozumiana kultura zbliża się znaczeniowo do terminu ,świadomość społeczna” jako przeciwieństwo „bytu społecznego" ${ }^{55}$. Trudno w takim wypadku pogodzić ją z innymi znaczeniami, jakie „kulturze” nadaje Runciman. Choć bowiem kładzie duży nacisk na odróżnienie kultury od społeczeństwa oraz ewolucji społecznej od ewolucji kulturowej ${ }^{56}$, to pojęcie kultury jest $\mathrm{u}$ niego niejasne $\mathrm{i}$ niewiele pomaga tu sięgnięcie do jego wcześniejszego Traktatu. Tam bowiem przyznaje, że będzie je stosował dwojako. Z jednej strony w odniesieniu do „tych cech organizacji społecznej, które wywodzą się ze zdolność pozaorganicznego transmitowania wiedzy”, z drugiej - do ,zawartości instytucjonalnych reguł (oczywiście »kulturowych"w pierwszym sensie), poprzez które zarządzane sa relacje panowania i współpracy w ludzkich społeczeństwach" ${ }^{57}$. Podkreślmy: $\mathrm{w}$ pierwszym znaczeniu to nie transmitowana wiedza stanowi kulturę, ale pewne cechy organizacji społecznej; w drugim - pewne informacje przejawiajace się instytucjonalnym kontekście, co wskazywałoby na jakąś społeczną ontologizację idei, w tym wypadku będących regulatywną nadbudową nad społeczeństwem.

W ostatniej pracy jednak przeciwstawia sobie kulturę i społeczeństwo nie tylko analitycznie, ale także historycznie ${ }^{58}$ - co oznacza, że istniał czas, gdy była kultura, a nie było społeczeństwa, potem zaś otwiera się pole ich koewolucji ${ }^{59}$. Wydaje się, że w Theory of Cultural and Social Selection w ogóle zrezygnował $\mathrm{z}$ drugiego rozumienia kultury, nie da się go bowiem pomyśleć w oderwaniu od instytucji (a zatem władzy, ról i ostatecznie społeczeństwa). Pozostaje zatem kultura jako cecha organizacji społecznej (występującej poza społeczeństwem). Sfera kultury sa to zachowania nabyte i niewymuszone, to świat rodziców, przyjaciól, mentorów, rodzeństwa i zdefiniowanych kulturowo przykładów. Role są rolami os obi sty mi, jeszcze niezinstytucjonalizowanymi. Oczywiście występuja przypadki graniczne, takie jak odwołujący się do nadprzyrodzonych inspiracji s t ały przywódca grupy uczniów lub starsi rodu, gdy mają konkretną władzę ekonomiczną, polityczną bądź militarną ${ }^{60}$. Wydaje się zatem, że kultura odpowiada znacznie uproszczonej i spłaszczonej koncepcji ,,wspólnoty” Ferdynanda Tönniesa. Czy tak rozumianą kulturę da się ostatecznie rozłożyć na proste jednostki informacji przekazywanej przez naśladownictwo, na memy? I może ważniejsze pytanie: czy taki rozkład byłby użyteczny poznawczo? Moim zdaniem, odpowiedź, przynajmniej na drugie pytanie, jest negatywna.

${ }^{54}$ W. G. Runciman, The Theory..., s. 31-32.

${ }^{5}$ S. Kozyr-Kowalski, Świadomość spoteczna, uczłowieczenie i ubytowienie wiedzy, w: Z. Stachowski (red.), Cztowiek i kultury. Liber amicorum. Studia poświęcone Profesorowi Mirostawowi Nowaczykowi, Polskie Towarzystwo Religioznawcze, Tyczyn 2001, s. 23-50; idem, Socjologia, społeczeństwo obywatelskie i państwo, WN UAM, Poznań 2004.

${ }^{56}$ W. G. Runciman, The Theory of Cultural..., s. 37.

${ }^{57}$ Idem, A Treatise..., s. 8.

58 Idem, The Theory of Cultural..., s. 40.

59 Ibidem, s. 139.

${ }^{60}$ Ibidem, s. 43. 
Tönniesowski obraz wspólnoty zawiera fundamentalny wymiar, który w dyskursie memetycznym ulega zatraceniu: wspólnoty opierają się na krwi, ziemi lub uwarunkowanym wykonywaniem tego samego zawodu podobieństwem duchowym ${ }^{61}$.

\section{PRZYKŁAD}

Na czym miałoby polegać badanie takiej składającej się z memów kultury? Należy, zdaniem Runcimana, wyjść od możliwie dokładnych danych na temat rozpowszechnienia danego memu w populacji ${ }^{62}$, czyli jego dystrybucji i postępującej reprodukcji. Nie należy zakładać, że dane wierzenie podzielane jest przez wszystkich w równym stopniu ${ }^{63}$. Następnie można spróbować odszukać taka wiązkę memów, która jest w danej populacji kluczowa, czyli wpływająca na wszelkie aspekty danej kultury, jak etos wojowników w starożytnej Grecji ${ }^{64}$. Zasadniczym pytaniem pozostaje jednak: jak wyjaśnić, porównując kultury, dlaczego właśnie ten, a nie inny mem został przyjęty ${ }^{65}$, albo też dlaczego nie został przyjęty, choć były po temu warunki ${ }^{66}$. Memy podlegaja selekcji, jednak w wielu przypadkach nie musi to być dobór ze względu na zgodność z rzeczywistością ${ }^{67}$. Korelacja w dystrybucji memów z ekonomiczna, polityczną i ideologiczną władzą skłania Runcimana do uwzględnienia w podejściu neodarwinowskim osiagnnięć socjologii wiedzy ${ }^{68}$. Warto przyjrzeć się temu ujęciu na jednym przykładzie: próbie wyjaśnienia przez Runcimana sukcesu wczesnego chrześcijaństwa.

Historia chrześcijaństwa - jego zdaniem - dzieli się na dwie części: w pierwszej mamy do czynienia z selekcją kulturowa, w drugiej - społeczną. Przed legalizacją przez Konstantyna w 312 r. chrześcijanie stanowili małą (o liczebności szacowanej przez Edwarda Gibbona na 5\% populacji Imperium Rzymskiego), nieznaną i świadomie apolityczną żydowską sektę. Zdaniem Runcimana dyfuzja chrześcijańskich memów dokonywała się wówczas poprzez nieformalne transmisje $\mathrm{w}$ miejscu pracy, na rogach ulic, między przyjaciółmi czy przez wpływ głowy domu. Jest to więc przypadek ewolucji kulturowej pod nieobecność czy przy nieistotności selekcji społecznej ${ }^{69}$.

Aby wyjaśnić sukces tej dyfuzji, Runciman skupia się na uchwyceniu osobliwości chrześcijaństwa. Jak się okazuje, nie było ono unikalne ani w swej ofercie życia pośmiertnego, ani monoteizmie, ani nawet w cudownych uzdro-

\footnotetext{
${ }^{61}$ F. Tönnies, Wspólnota $i$ stowarzyszenie. Rozprawa o komunizmie $i$ socjalizmie jako empirycznych formach kultury, tłum. J. Szacki, PWN, Warszawa 1988.

${ }^{62}$ W. G. Runciman, The Theory..., s. 92.

${ }^{63}$ Ibidem, s. 119.

${ }^{64}$ Ibidem, s. 121-123.

${ }^{65}$ Ibidem, s. 92.

${ }^{66}$ Ibidem, s. 124.

${ }^{67}$ Ibidem, s. 95.

68 Ibidem, s. 97.

${ }^{69}$ Ibidem, s. 131.
} 
wieniach. Wszystkie te idee i zjawiska istniały również $\mathrm{w}$ innych ruchach religijnych Cesarstwa Rzymskiego ${ }^{70}$. Kluczową różnicą w stosunku do otoczenia był chrześcijański nacisk na dobroczynność, dawanie jałmużny, pomoc więźniom i wszelkim osobom $\mathrm{w}$ potrzebie, włącznie $\mathrm{z}$ obcymi ${ }^{71}$. Strategia ta przynosiła chrześcijaństwu olbrzymie korzyści propagandowe ${ }^{72}$, ale niosła też ze sobą zagrożenie ze strony ,,pasażerów na gapę”, czyli jednostek, które wyłącznie cynicznie korzystają z pomocy, same niczego nie oferując. Zagrożeniem również mogli być różnego rodzaju szarlatani, w typie Peregrinosa opisanego przez pogańskiego satyryka Lukiana ${ }^{73}$. Zagrożenia te zostały zminimalizowane dzięki temu, że chrześcijanie tworzyli w istocie na tyle małe gminy, że znali się bezpośrednio i mogli się wzajemnie obserwować ${ }^{74}$. Wspólnoty te „,były ekskluzywne i totalistyczne na sposób, w jaki nie był żaden klub, czy nawet żadne pogańskie stowarzyszenie kultowe" ${ }^{\text {"75 }}$. A jednak były one bardziej otwarte niż gminy żydowskie ${ }^{76}$.

Sukces nowej religii tłumaczy więc Runciman ,,adaptatywnością (adaptedness) pewnego odróżnialnego pakietu zmutowanych czy rekombinowanych memów. Spośród nich najbardziej prawdopodobnym kandydatem jest dziwna norma bezwarunkowej dobroczynności, która w wyjątkowy - na tle pozostałych konkurencyjnych kultów czy sekt - sposób obejmowano obcych ${ }^{77}$.

Po konwersji Konstantyna zaczyna się drugi etap historii chrześcijaństwa ${ }^{78}$, na którym poza ewolucja kulturową zachodzi też socjoewolucja, związana z instytucjonalizacja, włączeniem przymusu (np. przymusowych konwersji), geopolityczną dyferencjacja, narzucaniem przez cesarza. Instytucjonalne sankcje stają się teraz tak samo ważne, jak interpersonalne naśladownictwo i uczenie się ${ }^{79}$.

Powyższy obraz (o ileż uboższy niż choćby metodologicznie pluralistyczne podejście Rodneya Starka $^{80}$ ) nasuwa szereg wątpliwości: skoro mem bezinteresownej dobroczynności był tak adaptatywny, to dlaczego nie upowszechnił się poza chrześcijaństwem (choć przypomnijmy, cesarz Julian Apostata podejmował takie próby)? Atomistyczne podejście do memów nie pozwala znaleźć na nie odpowiedzi. Konieczne bowiem byłoby przyznanie, że memy nie są autonomicznymi jednostkami, że czerpią swój sens z kontekstu, i tak mem bezinteresownej dobroczynności znajdywał uzasadnienie $\mathrm{w}$ innych memach chrześcijańskich (nauczaniu samego Jezusa oraz teologicznej interpretacji

${ }^{70}$ W. G. Runciman, The Diffusion of Christianity in the Third Century AD as a Case-Study in the Theory of Cultural Selection, ,European Journal of Sociology” 45, 2004, s. 16.

${ }^{71}$ W. G. Runciman, The Theory..., s. 133-134.

${ }^{72}$ Idem, The Diffusion of Christianity..., s. 17.

${ }^{73}$ Lukian z Samosaty, O zgonie Peregrinosa, w: M. Starowieyski (wybór), Pierwsi świadkowie. Pisma Ojców Apostolskich, tłum. Anna Świderkówna, Wydawnictwo M, Kraków 1998, s. 369-371.

${ }^{74}$ W. G. Runciman, The Theory..., s. 134.

75 Idem, The Diffusion of Christianity..., s. 10.

76 Idem, The Theory..., s. 132.

77 Ibidem, s. 135.

78 Ibidem s. 130-131; idem, The Diffusion of Christianity..., s. 5.

79 Idem, The Theory..., s. 135-136.

${ }^{80}$ R. Stark, The Rise of Christianity. How the Obscure, Marginal Jesus Movement Became the Dominant Religious Force in the Western World in a Few Centuries, HarperOne, New York 1997. 
jego śmierci). Podobnym uproszczeniem jest ostry rozdział procesu historycznego na ,jeszcze tylko kulturowy” i ,już także społeczny”. Zalążki instytucjonalizacji, a nawet stosunków koercyjnych w chrześcijaństwie pojawiły się na długo przed zwycięstwem Konstantyna przy Moście Mulwijskim, ich przesłanki dostrzec można już w późnych tekstach i modyfikacjach Nowego Testamentu, jak słynne „Niech niewiasty na zgromadzeniach milczą” (1 Kor 14, 34). W momencie swej konwersji Konstantyn miał już do czynienia z Kościołem zarządzanym przez prezbiterów, biskupów i patriarchów (Rzymu, Konstantynopola, Aleksandrii, Jerozolimy i in.), dysponującym sporymi majątkami. Czy rzeczywistość tę da się opisać wyłącznie w kategoriach swobodnego przepływu memów?

\section{KONKLUZJA}

Propozycja socjologii selekcjonistycznej zaprezentowana przez Waltera G. Runcimana jest niewątpliwie jedną $\mathrm{z}$ najodważniejszych prób przebudowania paradygmatu ewolucjonistycznego w socjologii, opartą na teorii Darwina. Niestety, Runciman na użytek tej operacji znacząco zredukował złożoność świata społecznego i kulturowego. Chociaż gdy pozostaje na gruncie socjologii porównawczej, posługuje się takimi kategoriami, jak: instytucje, systaksy, diady, to gdy przechodzi do stosowania teorii neodarwinowskiej (co miało być główną wartością dodaną jego teorii) społeczeństwo zmienia się w populację, a kultura - w pulę informacji memetycznej.

Tak rażące uproszczenie było możliwe tylko za dwojaką cenę: zerwania $\mathrm{z}$ tradycją socjologiczną oraz dość wąskiego sięgnięcia do wiedzy biologicznej, do jednego tylko z konkurencyjnych paradygmatów współczesnego neoewolucjonizmu, który już na gruncie świata organicznego okazuje się zdaniem wielu krytyków zbyt daleko idącym uproszczeniem. Przewagą darwinizmu na gruncie biologii była jego zdolność do integracji dotąd oderwanych koncepcji teoretycznych i obserwacji empirycznych. Jego triumf zaowocował odrzuceniem jedynie ewidentnie błędnych koncepcji. Tej zdolności integracyjnej darwinizm nie zachowuje w wersji ultraselekcjonistycznej, której admiratorem jest Runciman.

Podsumowując, uważam pomysł zastosowania teorii darwinowskiej do socjologii, choćby nawet tylko w kategorii narzędzia heurystycznego, za obiecujący, jednakże Runciman uczynił na drodze do jego realizacji ledwie niewielki krok.

dr Kamil M. Kaczmarek

Uniwersytet im. Adama Mickiewicza $w$ Poznaniu

camillos@amu.edu.pl 


\section{THEORY OF CULTURAL AND SOCIAL REVOLUTION AS VIEWED BY WALTER GARRISON RUNCIMAN}

\section{Summary}

Walter Garrison Runciman's recent work The Theory of Cultural and Social Selection is a new attempt to create a sociological theory of evolution based on neodarwinism. It is also an important step extending beyond the previous propositions of dual inheritance theory as well as memetics. However, selectionism, a paradigm developed in it by the use of simplified evolutionary biology, requires a reduction of a society to simple population of heritable units of selection and a similar reduction of culture. Runciman has failed to convincingly integrate the neodarwinian populational approach with his own sociological system. One of the main reason for his failure is, in my opinion, his radical break with the classical tradition of sociology. 
Copyright of Journal of Law, Economics and Sociology is the property of Faculty of Law and Administration of Adam Mickiewicz University in Poznan and its content may not be copied or emailed to multiple sites or posted to a listserv without the copyright holder's express written permission. However, users may print, download, or email articles for individual use.

Właścicielem praw autorskich do „Ruchu Prawniczego, Ekonomicznego i Socjologicznego” jest Wydział Prawa i Administracji Uniwersytetu im. Adama Mickiewicza w Poznaniu. Zawartość czasopisma nie może być kopiowana, przesyłana do innych stron internetowych bądź zamieszczana na blogach bez pisemnej zgody wydawcy. Niemniej artykuły można drukować, kopiować lub przesyłać w formie elektronicznej na własny użytek. 